\title{
Chemical Extraction and Property Analyses of Marula Nut Oil for Biodiesel Production
}

\author{
Jerekias Gandure ${ }^{*}$, Clever Ketlogetswe \\ Mechanical Engineering Department, University of Botswana, Gaborone, Botswana \\ E-mail: \{ ${ }^{*}$ gandurej, ketloget\}@mopipi.ub.bw \\ Received May 24, 2011; revised June 19, 2011; accepted June 25, 2011
}

\begin{abstract}
To identify and develop alternative and renewable sources of fuel for the transport sector is a present challenge for engineers and researchers. This work was carried out to assess yield of marula (Sclero carrya/birrea) nut and chemical properties of crude marula nut oil for biodiesel production in Botswana. Chemical extraction of marula oil was done to establish actual oil content by use of hexane/iso-propyl alcohol solvent in a soxhlet set up. Distillation was carried out on a Rotavapor system prior to oil purging using nitrogen gas. The results indicated that marula nuts have about $58.6 \%$ oil content. Characterisation of the extracted crude oil was carried out to determine its chemical composition using the Waters GCT Premier Time of Flight (TOF) Mass Spectrometer (MS) coupled to the Agilent 6890 N Gas Chromatography (GC) system. Ethyl oleate (ethyl ester) was found to be the dominant fatty acid. Trans-Oleic acid was also abundant but could not be quantified because it was not found in the standard mixture. Crude marula oil was also found to have an ester content of $93.7 \%$, acid value of $1.4 \mathrm{mg} \mathrm{KOH} / \mathrm{g}$, and free fatty acid content of $0.7 \%$. These results are marginally out of specifications for biodiesel by international standards, implying that crude marula oil is a potential substrate for biodiesel production.
\end{abstract}

Keywords: Marula Oil, Chemical Extraction, Chemical Properties

\section{Introduction}

The persuit for biodiesel production in Botswana is motivated by factors including volatile oil prices, potential for job creation, fuel security and economic diversification. The desire to establish energy self-reliance and to develop alternatives to finite fossil fuel resources has stimulated development of fuel technologies that are based on use of renewable agriculture based materials as feedstocks. In the case of renewable fuels for compression ignition (diesel) engines, the majority of efforts to date have focused on biodiesel, which consists of alkyl esters of fatty acids. Biodiesel has been shown to give engine performance that is generally comparable to that of conventional diesel fuel while reducing engine emissions of particulates, hydrocarbons and carbon monoxide [1-3]. Biodiesel can be produced from any material that contains fatty acids, bonded to other molecules or present as free fatty acids. As a result various vegetable oils can be used as feedstocks for biodiesel production. The choice of feedstock is based on such variables as local availa- bility, cost, government support and performance as a fuel [4].

This work seeks to establish yield and properties of crude marula nut oil of Botswana's climatic conditions as a potential substrate for biodiesel production. Marula tree is indigenous to most parts of Southern Africa. In Botswana, it is widely distributed all over the country, but it is concentrated in the north eastern part of the country. The tree grows in warm and dry climatic conditions, and produce oval fruits that turn pale yellow when ripe. The fruit consists of a hard woody seed covered by pulp and juice which makes the fleshy part of the fruit. The hard seed contains mostly two oil rich nuts (kernel) which can be eaten as a snack. However, in some parts of Botswana the nut oil is currently being used to produce cosmetic ointments by small groups of rural communities. There is now a worldwide trend to explore wild plants for oil to augment the already existing sources of oil. The fact that the marula tree grows in drier parts where common oil seeds cannot thrive has stirred interest in marula nut oil as a valuable renewable source of energy. 
This has led to the evaluation of marula nut oil as a potential substrate for biodiesel production.

\section{Materials and Methods}

\subsection{Chemical Extraction}

Chemical extraction was carried out to establish the actual oil content (yield) of marula nut. The process had five stages namely seed grinding, solvent extraction, filtration, distillation and purging. $200 \mathrm{~g}$ of marula nuts were ground into powder using a coffee grinder. The grinder was loaded with $50 \mathrm{~g}$ of marula nuts at a time and run for about 30 seconds. The operation was repeated to increase the degree of fineness of the powder. The powder was then used in the solvent extraction process. The solvent was prepared by mixing $300 \mathrm{ml}$ of hexane and $100 \mathrm{ml}$ of isopropyl alcohol in a $500 \mathrm{ml}$ flask. This formula ensures total extraction of all lipids as hexane extracts all nonpolar lipids and iso-propyl alcohol polar lipids. $3 \mathrm{~g}$ of anti-bumping stones (boiling stones) were added to the mixture to ensure non-violent boiling of the solvent during oil extraction. $74.6 \mathrm{~g}$ of powdered sample was loaded in a thimble and placed inside a soxhlet. A soxhlet cover, condenser and heating mantle were mounted to complete the soxhlet solvent extraction set. The solvent was heated to boiling temperature and maintained in that phase for the entire extraction process (6 hours). After 7 syphones, the extracted liquid became clear, indicating that there was no more oil in the sample. The process was stopped and solvent/oil mixture was allowed to cool for about 3 hours. Filtration was done to eliminate any possibility of solid particles in the oil rich solvent. The separation of solvent from the oil was achieved through distillation under vac- uum pressure using a Rotavapor (rotary evaporator) shown in Figure 1.

The heating bath of the rotavapor used distilled water maintained at $40^{\circ} \mathrm{C}$ for the entire separation process. The condenser used water that is slightly above freezing temperature and was maintained at that temperature by ice blocks. This process should ideally extract all the solvent, starting with hexane and then iso-propanol (due to the double bond). To ensure that no trace of solvent remains in the oil, the oil was purged with nitrogen (nitrogen drying) for approximately 40 minutes. Nitrogen is used for this purpose because it is inert and does not react with oil compounds.

\subsection{Oil Characterization}

Crude marula oil extract from solvent extraction was used in its natural state for fatty acid profile analysis. The oil will be converted into biodiesel by transesterification process in the second phase of the study, and the fatty acid profile analysis will be repeated to compare changes in properties. The composition of marula nut oil was analysed using the Waters GCT premier Time of Flight (TOF) mass spectrometer coupled to the Agilent $6890 \mathrm{~N}$ gas chromatograph system. The instrument has high sensitivity and fast acquisition rates. In addition, the National Institute for Standards and Technology (NIST) developed Automated Mass Spectral Deconvolution and Identification System (AMDIS) software package, (chemdata.nist.gov/mass-spc/amdis) was used for peak identification. AMDIS extracts spectra for individual components in a GC-MS data file and identifies target compounds by matching these spectra against a reference library, in this case the NIST library. AMDIS also allows

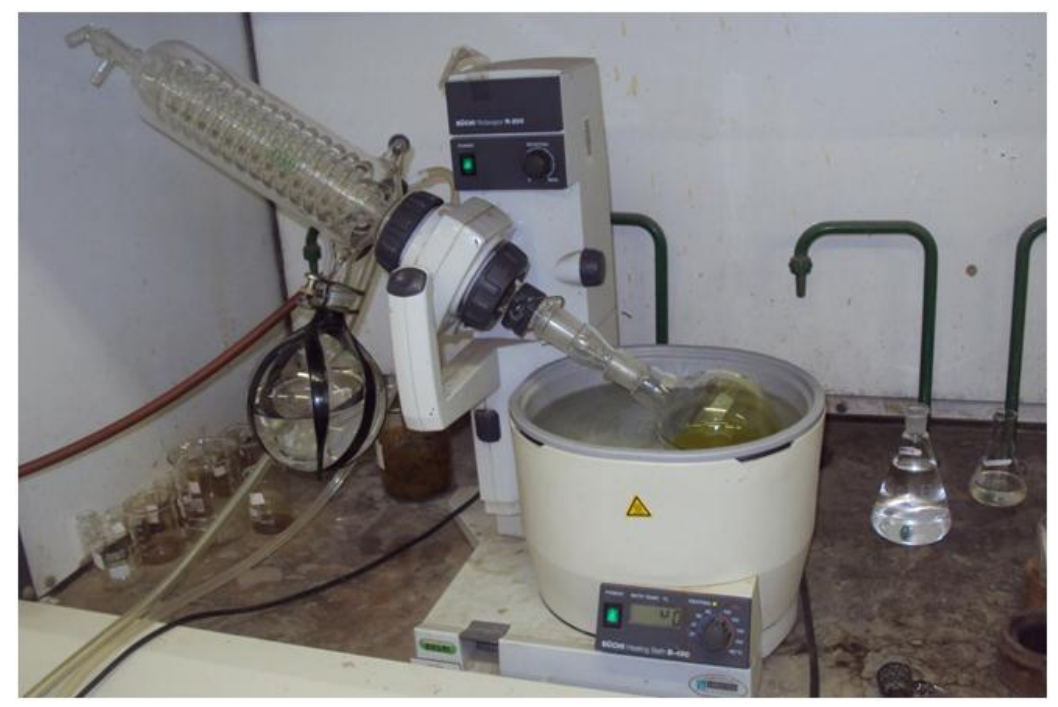

Figure 1. Rotavapor. 
creation of personal libraries where routine analyses of compounds is encountered.

\subsubsection{Gas Chromatograph Conditions}

$1 \mu \mathrm{L}$ of the sample extract was injected into the system using an auto-injector. The injector temperature was set at $260^{\circ} \mathrm{C}$ in the splitless mode. Helium was used as the carrier gas at a flow rate of $1 \mathrm{ml} / \mathrm{min}$. The separation was achieved using a 30 meter DB5-MS column. The oven temperature was kept at the initial $100^{\circ} \mathrm{C}$ for 2 minutes, and then gradually increased from $100^{\circ} \mathrm{C}$ to $290^{\circ} \mathrm{C}$ at a rate of $10^{\circ} \mathrm{C}$ per minute. The total run time was 35 minutes.

\subsubsection{Mass Spectrometer Conditions}

The Mass Spectrometer (MS) conditions that were employed were a positive polarity of electron ionization (EI), a source temperature of $180^{\circ} \mathrm{C}$, an emission current of $359 \mathrm{uA}$. Other MS conditions including electron energy and resolution were set by the system auto tune function. Detection was by the Micro Channel Plate detector (MCP) whose voltage was set at $2700 \mathrm{~V}$. The oil composition was identified and quantified using the NIST (2005) mass spectral library using a combination of the Masslynx acquisition /data analysis software and the AMDIS by NIST.

\subsection{Oil Acidity}

Acid value measurement of crude marula oil was done by titration according to ASTM method D664 [5]. 125 $\mathrm{ml}$ of solvent, consisting of 50\% isopropyl alcohol and $50 \%$ toluene, was prepared in a $600 \mathrm{ml}$ beaker. $5 \mathrm{~g}$ of marula oil was added to the beaker, followed by $2 \mathrm{ml}$ of phenolphthalein indicator. Beaker contents were titrated with $0.1 \mathrm{M} \mathrm{KOH}$ to the first permanent pink color.

\section{Results and Discussions}

\subsection{Marula Nut Oil Content (Yield)}

The purged marula oil was weighed and had a weight of
$43.6839 \mathrm{~g}$. This was expressed as a percentage of the weight of the original sample, $74.6000 \mathrm{~g}$, used for soxhlet extraction. This yielded an oil content of 58.558\%. The efficiency of mechanical equipment used for large scale oil extraction can thefore be benchmarked and improved towards reaching the yield from chemically extraction. Marula nut's high oil content, coupled with good chemical properties for biodiesel production, indicates that it deserves consideration for biodiesel feedstock in Botswana.

\subsection{Characterization of Crude Marula Oil}

Tests were conducted in a systematic study to establish the fatty acid profile of crude marula oil using procedure and conditions described in Section 2.2. The results for marula oil composition were compared with that for a standard sample of vegetable oils prepared by AccuStandard. For simplicity, only a single set of sample results obtained from these experiments are presented and discussed in this Section. This enables the main findings of the study to be identified. The fatty acids and esters detected, which are naturally present in the oil, are presented in Table 1.

The fatty acid profile of crude marula oil indicates a good number of fatty acids and esters, half of which were not found in the standard sample. The observation suggests the uniqueness of this indigenous oil. The fatty acid that was detected to be most abundant is ethyl oleate (ethyl ester) with a concentration of 223.5 ppm (by weight per unit volume). Other compounds had substantial presence which could improve if concentrated through processing. Figure 2 represents the mass spectrum of ethyl oleate.

The spectrum in Figure 2 indicates major peaks of the compound, together with minor peaks that may be due to fragmentation of the same compound resulting from labile ester linkages possibly present in the compound, or presence of another compound that is not fully resolved. The mass spectrum of ethyl oleate is an intensity/relative abundance (\%) versus mass-to-charge ratio $(\mathrm{m} / \mathrm{z})$ plot representing a chemical analysis of the compound. Gene-

Table 1. Crude marula oil fatty acid profile.

\begin{tabular}{|c|c|c|c|c|}
\hline No. & Fatty Acid Detected & $\begin{array}{c}\text { Status (in standard } \\
\text { mixture) }\end{array}$ & $\begin{array}{c}\text { Concentration } \\
(\mathrm{ppm} \mathrm{w/v})\end{array}$ & Comments \\
\hline 1 & Palmitic acid & No & - & Nil \\
\hline 2 & Palmitic acid (methyl ester) & Yes & 17.4 & Nil \\
\hline 3 & Palmitic acid (ethyl ester) & Yes & 13.3 & Nil \\
\hline 4 & Trans-oleic acid & No & - & Nil \\
\hline 5 & Ethyl Oleate (Ethyl ester) & Yes & 223.5 & Nil \\
\hline 6 & Oleic acid, 3-hydroxypropyl ester & No & - & Nil \\
\hline 7 & Olein, 1-mono & No & - & 2 isomers detected \\
\hline
\end{tabular}




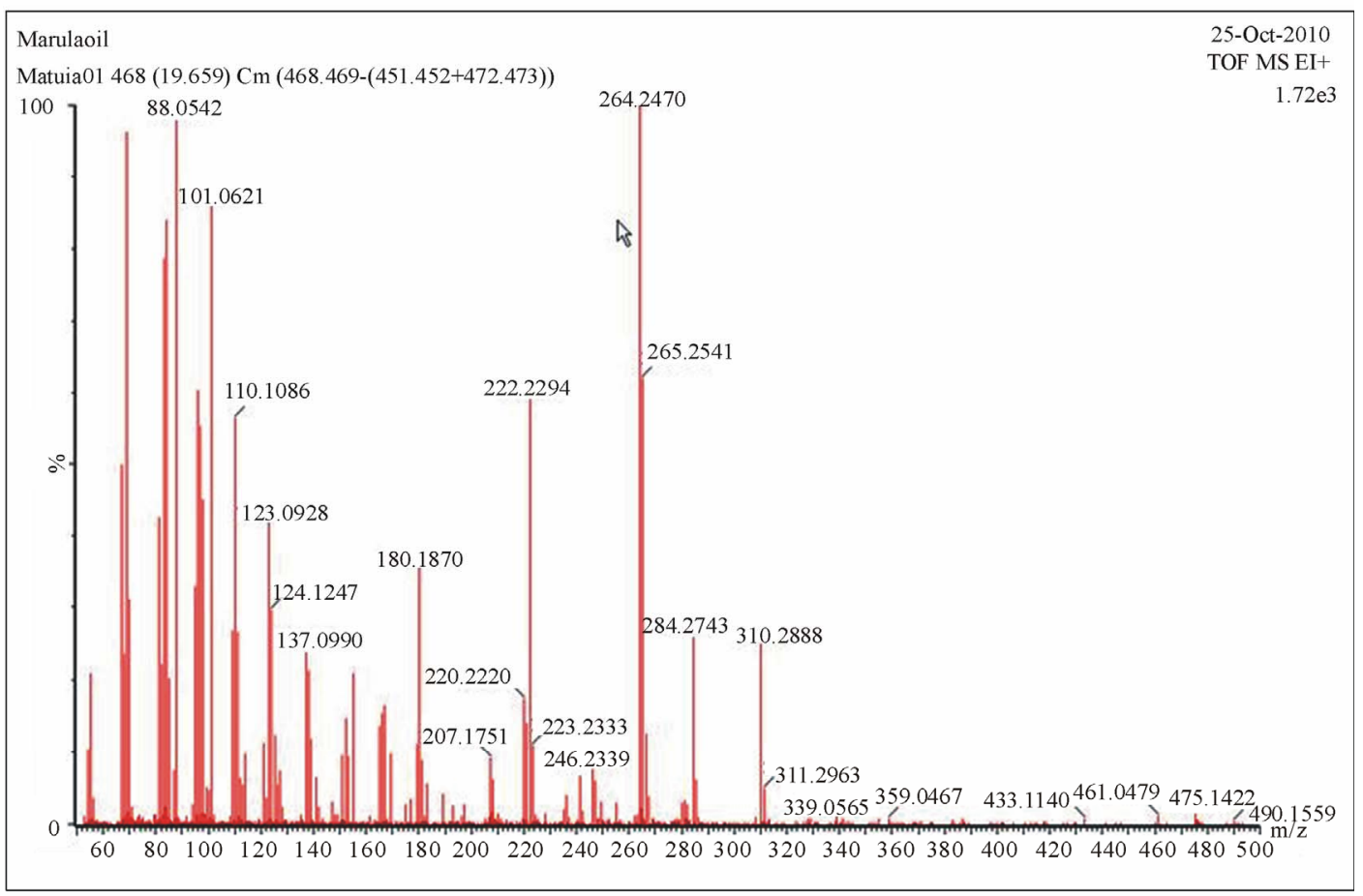

Figure 2. Ethyl oleate.

rally, the mass spectrum of a sample is a pattern representing the distribution of ions by mass (mass-tocharge ratio) in a sample, usually acquired using a mass spectrometer. Not all mass spectra of a given substance are the same. Some mass spectrometers break the analyte molecules into fragments; others observe the intact molecular masses with little fragmentation. A mass spectrum can represent many different types of information based on the type of mass spectrometer and the specific experiment applied; but all plots of intensity versus mass-to-charge are referred to as mass spectra.

Based on the data in Table 1 and the results in Figure 2, crude marula nut oil composition depicts characteristics of a good fuel, even before it is transesterified into biodiesel. According to Kyamuhangire [6], vegetable oil can be used either directly in internal combustion engines or converted into blended biodiesel. In response to the above observations, the crude marula oil will be tested for performance as a fuel in a variable compression ignition engine in the second phase of the investigation.

\subsection{Ester Content of Crude Marula Oil}

According to European Standards for Biodiesel, EN 14214, a fuel should have a minimum ester content of $96.5 \%$ in order to be used as biodiesel [7]. To establish the ester content in crude marula oil, the retention times for the fatty acids listed in Table 1 were detected by use of Masslynx software tools and were used to identify compound peaks in the chromatogram. This enabled the peak areas of the esters in the marula sample to be summed up and expressed as a percentage of total sum of peak areas of all compounds in crude marula oil sample. Table $\mathbf{2}$ and Figure $\mathbf{3}$ represent fatty acid retention times and peak areas, and chromatogram respectively.

The data summarised in Table 2 yields an ester content of $93.7 \%$ in crude marula oil. This value could improve if peak areas for trans-oleic acid, palmitic acid and its esters were considered, but their retention times could not be matched with their peaks. However, an ester content of $93.7 \%$ for crude marula oil is quite close to the recommended minimum of $96.5 \%$, implying that transesterifying the oil into biodiesel is likely to improve the ester content to above the minimum recommended value.

\subsection{Acidity of Crude Marula Oil}

Three titrations were carried out and the average titration value was $1.25 \mathrm{~mL}$. The acid value of the oil was determined using equation 1.

Acid Value, $A V=[(56.1 \times N) / W] \times$ Titration value

where 56.1 = molecular weight of $\mathrm{KOH}$

$N=$ molarity of the base

$W=$ weight of sample (marula oil) in grams

Titration value $=$ number of $\mathrm{mL}$ of $\mathrm{KOH}$ that neutralised sample beaker.

The computed acid value of crude marula oil was 1.4 $\mathrm{mg} \mathrm{KOH/g}$, implying a percentage free fatty acid con- 
Table 2. Fatty acid retention times and peak areas.

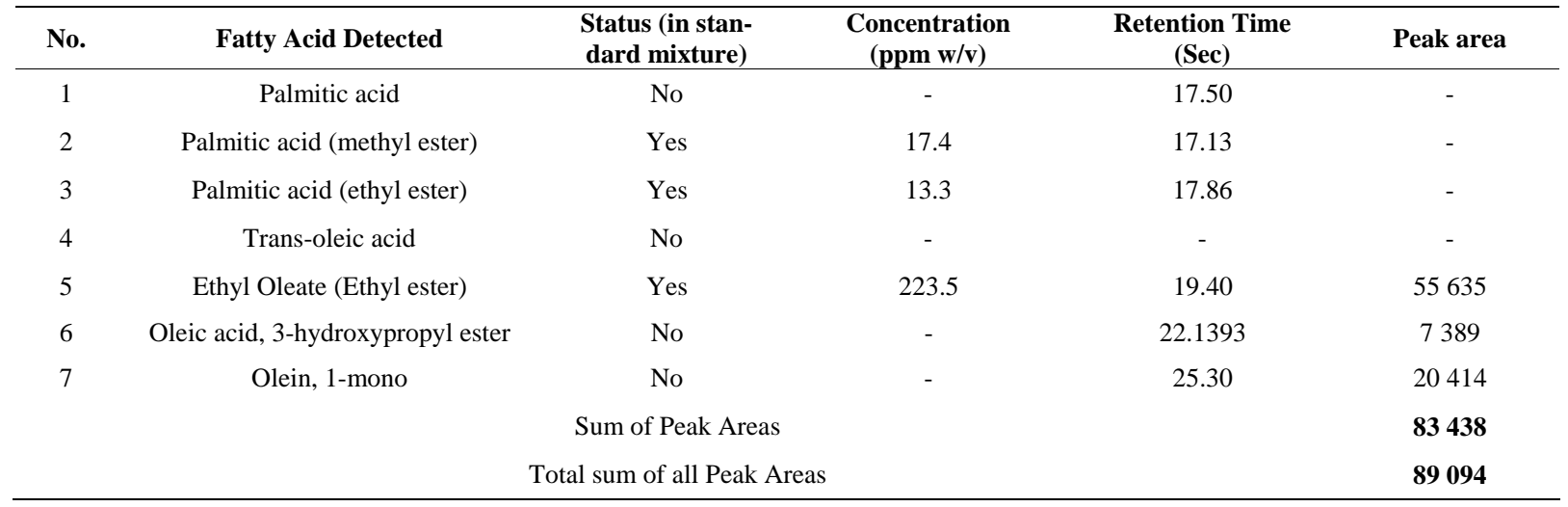

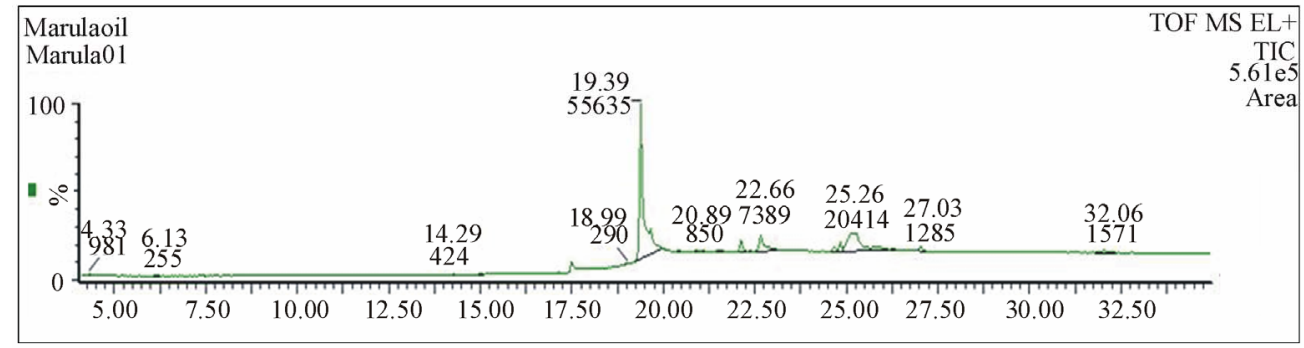

Figure 3. Chromatogram.

tent of $0.7 \%$ according to equation 2. ASTM D6751 stipulates that the total acid number should be $0.50 \mathrm{mg}$ $\mathrm{KOH} / \mathrm{g}$ max.

Percentage Free Fatty Acid $(\%$ FFA $)=0.5 \times$ Acid Value

Generally, when the FFA level is less than $1 \%$, and certainly if it is less than $0.5 \%$, the FFAs can be ignored. A range between $2 \%-3 \%$ of FFA may be the limit if traces of water are present. The free fatty acid content of $0.7 \%$ obtained in this work for crude marula oil compares very closely with specification for processed biodiesel. This indicates high potential of crude marula oil for use as feedstock for production of biodiesel.

\section{Conclusions}

A study to establish the actual oil content (yield) of marula nuts was carried out chemically using soxhlet solvent extraction. The study also examined chemical composition and some properties of crude marula oil to assess suitability for use as feedstock for biodiesel production.

From the results of the study, it can be concluded that.

1) The oil content of marula nut is about 59\%. This is a relatively high yield desirable for a potential feedstock for biodiesel production.

2) Crude marula nut oil has chemical properties that can enable it to function as biodiesel in IC diesel engines. This implies that transesterifying crude marula nut oil under standard conditions has potential to produce biodiesel of international quality standard.

3) Trans-Oleic acid is the major fatty acid in crude marula nut oil. The second most abundant free fatty acid detected is Ethyl Oleate which is an ethyl ester. The ester content of crude marula oil is about $94 \%$. Other free fatty acids detected include Oleic acid, 3-hydroxypropyl ester, Palmitic acid (methyl ester), Palmitic acid (ethyl ester), suggesting that crude marula nut oil has strong characteristics required for biodiesel fuel.

4) The acid value of crude marula oil is about $1.4 \mathrm{mg}$ $\mathrm{KOH} / \mathrm{g}$, implying a free fatty acid (FFA) content of about $0.7 \%$. This suggests that crude marula nut oil makes a good feedstock for production of biodiesel.

\section{Acknowledgements}

We acknowledge support of the University of Botswana, and the Ministry of Wildlife, Tourism and Environment who granted a research permit for this work.

\section{References}

[1] M. S. Graboski and R. L. McCormick, "Combustion of Fat and Vegetable Oil Derived Fuels in Diesel Engines," Progress in Energy and Combustion Science, Vol. 24, 
1998, pp. 125-164.

doi:10.1016/S0360-1285(97)00034-8

[2] P. M. Adriano, C. T. Richard, M. Luciano, C. Jonas and F. A. Dejanira, "Biodegradability of Diesel and Biodiesel Blends," African Journal of Biotechnology, Vol. 7, No. 9, 2008, pp. 1323-1328.

[3] C. Shu-Mei, H. Yuh-Jeen, C. Shunn-Cheng and Y. Hsi-Hsien, "Effects of Biodiesel Blending on Particulate and Polycyclic Aromatic Hydrocarbon Emissions in Nano/Ul-trafine/Fine/Coarse Ranges from Diesel Engine,” Aerosol and Air Quality Research, Vol. 9, No. 1, 2009, pp. 18-31.

[4] M. J. Haas, A. J. Mc Aloon, W. C. Yee, T. A. Foglia, “A
Process Model to Estimate Biodiesel Production Costs," Bioresource Technology, Vol. 97, 2006, pp. 671-678. doi:10.1016/j.biortech.2005.03.039

[5] J. D. Mac Farlane, "Determining Total Acid in Biodiese," 2011. www.LaboratoryEquipment.com.

[6] W. Kyamuhangire, "Perspective of Bioenergy and Jatropha in Uganda," International Consultation on Pro-Poor Jatropha Development, Casa Son Bernadu, via Lawrentina, Rome, Vol. 289, 2008.

[7] Committee for Standardization, "European Standards for Biodiesel,” 2010. www.EN14214.com. 